\title{
A comunicação dos treinadores de futebol de equipes infanto-juvenis amadores e profissionais durante a competição
}

\author{
Fernando Jorge Lourenço dos Santos \\ Pedro Jorge Richheimer Marta de Sequeira \\ José de Jesus Fernandes Rodrigues \\ Escola Superior de Desporto de Rio Maior, Rio Maior, Portugal
}

\begin{abstract}
Resumo: No futebol, a comunicação durante a competição é a forma que o treinador utiliza para transmitir informação com o objetivo de otimizar o rendimento dos jogadores. Pretendemos caracterizar e comparar os comportamentos de instrução dos treinadores de times de jogadores infanto-juvenis e adultos. Foram filmados dez treinadores (cinco de equipes infanto-juvenis e cinco de equipes de adultos) em dezenove jogos. O sistema de observação para recolha de dados relativos ao comportamento de instrução foi o SAIC. Os resultados obtidos demonstram a existência de diferenças entre os treinadores de equipes infantojuvenis e de adultos no que diz respeito à instrução, à atenção e ao comportamento motor reativo.
\end{abstract}

Palavras-chave: observação; comportamento; futebol; comunicação.

\section{The coach's communication with scholastic and adult teams during soccer matches}

\begin{abstract}
During soccer competitions, coaches communicate with the players to address information that should optimize performance of the players. Our purpose is to characterize and compare the coach behaviors during instruction to adults and scholastic teams. Ten coaches (five from scholastic soccer teams and five from adult teams) were videotaped during nineteen games. The observation system used for data collection of instruction behaviors was the SAIC. The results indicate the existence of differences between coaches from scholastic soccer teams and five from adult teams with regard to instruction, attention and reactive motor behavior.
\end{abstract}

Keywords: observation; behavior; soccer; communication.

\section{Introdução}

Com este estudo pretendemos caracterizar e comparar a atividade pedagógica de treinadores durante a direção de times adultos e infantojuvenis em competição; verificar a atenção dos atletas nas equipes em contexto competitivo, bem como analisar o comportamento motor reativo resultante do aporte de informação.

O treinador deve exercer a sua função tendo em vista as características dos atletas e os objetivos do contexto em que está inserido. Para Coté et al. (2007), o treinador excelente é aquele que desenvolve as suas competências tendo em vista o contexto em que trabalha, pois para as diversas etapas de desenvolvimento existem exigências diferentes. Smith e Smoll (1997) defendem que existem diferenças entre o modelo de desporto profissional, em que a vitória e os ganhos financeiros assumem uma grande importância, e o modelo de formação desportiva onde dever ser promovido um contexto positivo para as crianças e jovens, em que deve ser estimulado o esforço e a aprendizagem, tendo em vista 0 divertimento, satisfação de pertencer a uma equipa, aquisição de novas competências desportivas, aumento da autoestima e reduzir o medo de falhar.
Carter e Bloom (2009) afirmam que os treinadores desempenham funções diversas, como orientar o treino das técnicas específicas da modalidade, fornecem instrução e feedback, acompanhamento da aprendizagem e do desempenho dos atletas. Todas essas funções são planejadas e projetadas para ajudar os atletas a atingirem o seu potencial.

Segundo Mesquita et al. (2008), o treinador somente poderá ser realmente eficaz num contexto específico em função da natureza e particularidades do desporto em causa, devendo ser desenvolvida investigação suplementar para discutir com maior propriedade os resultados obtidos na pesquisa.

Os bons treinadores se são de sucesso, diferenciam-se dos restantes devido à sua capacidade de comunicação. Launder e Piltz (1999) afirmam que a condução eficiente da equipe durante uma competição é um elemento importante dado o impacto, positivo ou negativo, que pode ter mesmo para além daquele jogo.

Segundo Santos e Rodrigues (2008), é importante que a comunicação em competição seja eficaz para o treinador tendo em vista a conquista da sua liderança perante o grupo de 
trabalho e para o jogador obter a motivação, autoconfiança e a autoestima necessárias a um ótimo rendimento. Independentemente do estilo de liderança, é importante o treinador dominar técnicas de comunicação para uma eficaz gestão do grupo/equipe.

Gilbert et al. (1999) esclarecem as decisões do treinador durante o jogo, levando-nos a considerar a importância das técnicas de comunicação nos treinadores, pois irão facilitar a interação com os seus jogadores, tornando-a eficaz, tendo em vista os resultados pretendidos.

Moreno et al. (2005), ao estudarem a eficácia da comunicação verbal dos treinadores de voleibol em jogo, levam-nos a considerar as dificuldades pelos atletas na recepção da informação, sua quantidade, bem como a atenção dos atletas e o seu conhecimento anterior.

Em competição, a eficácia das instruções fornecidas pelo treinador depende se os atletas conseguem reter e perceber a informação, levando a um melhor nível de performance. A capacidade de processar a informação por parte dos atletas pode ser afetada pelo nervosismo e ansiedade experimentadas em competição. Também a quantidade e natureza da informação transmitida pelo treinador são fatores que afetam o nível de retenção e compreensão dos atletas (Mesquita et al., 2008).

Santos e Rodrigues (2008), analisando treinadores de jogadores veteranos, registraram uma quantidade de informação de 4,7 Ul/min. Os mesmos autores, de acordo com a sua amostra, estabeleceram uma escala para a quantidade de informação emitida pelo treinador: pouca instrução (1 a $3 \mathrm{UI} / \mathrm{min}$ ), média de instrução (3 a 5 $\mathrm{UI} / \mathrm{min}$ ) e muita instrução (5 a $10 \mathrm{UI} / \mathrm{min})$. Ramirez e Diaz (2004) encontraram em treinadores do setor de formação desportiva uma quantidade de informação de 4,2 Ul/min.

Moreno e Alvarez (2004) afirmam que a informação dos treinadores deve ser preferencialmente tática, individual, de caráter fortemente positivo e centrado na própria equipe e na equipe adversária.

Santos e Rodrigues (2008), avaliando treinadores da II divisão B no escalão de profissionais, verificaram que a instrução é preferencialmente tática $(45,1 \%)$, aparecendo o conteúdo psicológico como segunda categoria com mais acontecimentos $(33,2 \%)$, dirigida ao atleta $(72,5 \%)$, com o objetivo prescritivo $(84,1 \%)$ e de forma predominantemente auditiva (66\%).

Ramirez e Diaz (2004), ao analisarem treinadores de futebol dos escalões de iniciados e juvenis, verificaram que $36,27 \%$ da informação emitida foi de conteúdo tático, 30,69\% dedicada à motivação, $12,77 \%$ relacionada com o esforço físico, $7,36 \%$ às questões técnicas e $5,15 \%$ à arbitragem.

\section{Métodos}

A nossa amostra foi composta por dez treinadores de futebol (cinco de equipes de adultos - II e III divisão nacional; e cinco de equipes infanto-juvenis - campeonato nacional de infantis e juvenis, dos 13 aos 16 anos) com curso de treinadores da modalidade, licenciatura em educação física e desporto e mais de cinco anos de experiência no escalão. Foram filmados dois jogos por treinador, sempre em situação de equipe da casa (19 jogos, 9 de adultos e 10 nos escalões de iniciação). Após os treinadores terem aceitado participar no estudo, e a fim de serem marcadas as filmagens, foi-lhes perguntado quais os jogos em casa que haveria expectativa de vitória. Para a coleta de dados na competição, foi colocado um microfone na lapela do treinador, com um receptor de som ligado a uma câmara de vídeo que estava colocada no lado oposto do banco de suplentes, para garantir a validade dos resultados. Para uma melhor interpretação das instruções fornecidas pelo treinador durante 0 jogo, utilizamos uma segunda câmara para filmar o jogo. A coleta de dados realizou-se nas épocas 2008/2009 e 2009/2010. O instrumento utilizado para categorizar a instrução emitida pelo treinador durante a totalidade da competição foi o Sistema de Análise da Instrução em Competição (SAIC), validado por Santos e Rodrigues (2008). O SAIC é constituído por quatro dimensões (objetivo, forma, direção e conteúdo). Adicionamos a este instrumento mais duas dimensões relativas à atenção dos atletas, grupo de atletas, equipe e comportamento motor reativo.

A validade da observação dos diferentes jogos do nosso estudo foi verificada com o mesmo observador em diferentes momentos (fidelidade intra-observador) e com diferentes observadores (fidelidade inter-observadores) a fim de verificar se as diferentes categorias foram observadas $e$ entendidas da mesma forma. Foram verificados valores de fidelidade através do teste Kappa de Cohen, acima dos $75 \%$.

No tratamento dos dados foi utilizada a estatística descritiva para caracterização do comportamento de instrução dos treinadores observados. Relativamente à comparação entre resultados dos treinadores de equipes infantojuvenis e treinadores de equipe de adultos, dado que a amostra não atendeu o critério de normalidade, foi utilizada o teste não-paramétrico, 
U-Mann Whitney, com um intervalo de significância menor que 0,05 . Os aspectos éticos, consagrados na Declaração de Helsínquia, foram assegurados pela aprovação do Comitê de Ética da instituição (011/2012).

\section{Resultados}

Treinadores de equipes infanto-juvenis

A quantidade média de instrução manifestada pelos treinadores de equipes infanto-juvenis da nossa amostra foi de 6,30UI/Min.

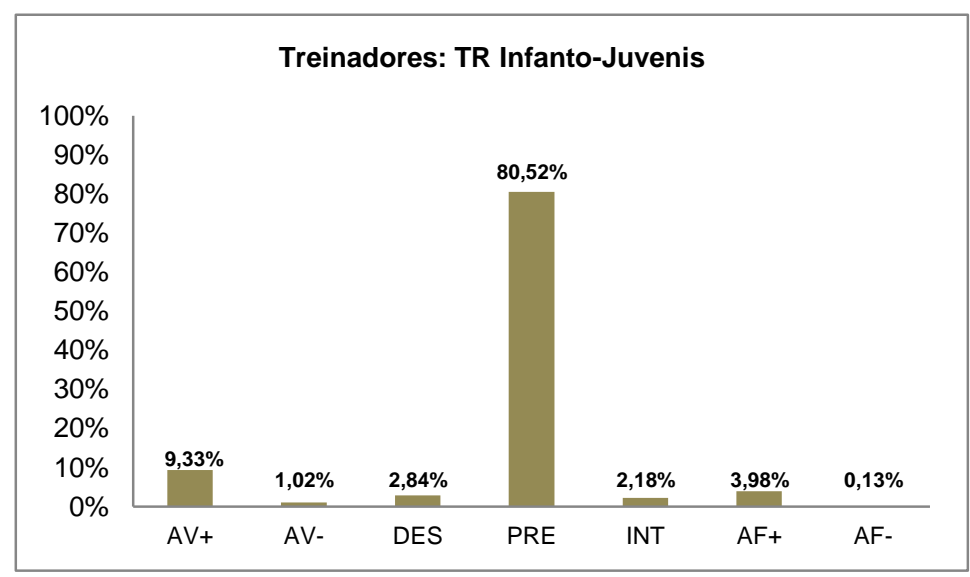

Figura 1. Valores em porcentagem da dimensão objetivo da instrução durante a competição (AV+ - Avaliativo Positivo; AV- - Avaliativo Negativo; DES - Descritivo; INT - Interrogativo; AF+ - Afetivo Positivo; AF- - Afetivo Negativo).

Relativamente à dimensão objectivo (Figura 1), a instrução foi predominantemente prescritiva $(80,52 \%)$, seguindo-se a categoria avaliativo positivo (9,33\%), afetividade positiva $(3,98 \%)$, descritiva $(2,84 \%)$ e interrogativa $(2,18 \%)$.

Os treinadores de equipes infanto-juvenis da nossa amostra emitiram preferencialmente instrução de forma auditiva (73,40\%), seguindo-se a forma auditiva-visual $(25,91 \%)$ e visual $(0,69 \%)$.

A direção do aporte de informação nos treinadores de equipes infanto-juvenis foi predominantemente ao atleta $(81,95 \%)$, seguindose à equipe $(9,42 \%)$, atletas reservas $(3,74 \%)$ e grupo de meio de campo (2,70\%). Dos dados apresentados ressaltamos também a preocupação dos treinadores em emitir informação direcionada aos setores da equipe $(4,47 \%)$ a fim de conseguir uma melhor articulação para uma eficaz resolução das situações de jogo.

O conteúdo da instrução dos treinadores de equipes infanto-juvenis observados foi predominantemente tático $(50,90 \%)$, seguindo do conteúdo psicológico (27,38\%), sem conteúdo $(13,76 \%)$, técnico $(4,49 \%)$ e físico $(2,52 \%)$. Valores mais baixos foram registrados para 0 conteúdo relativo à equipe adversária $(0,63 \%)$ e equipe de arbitragem $(0,22 \%)$.

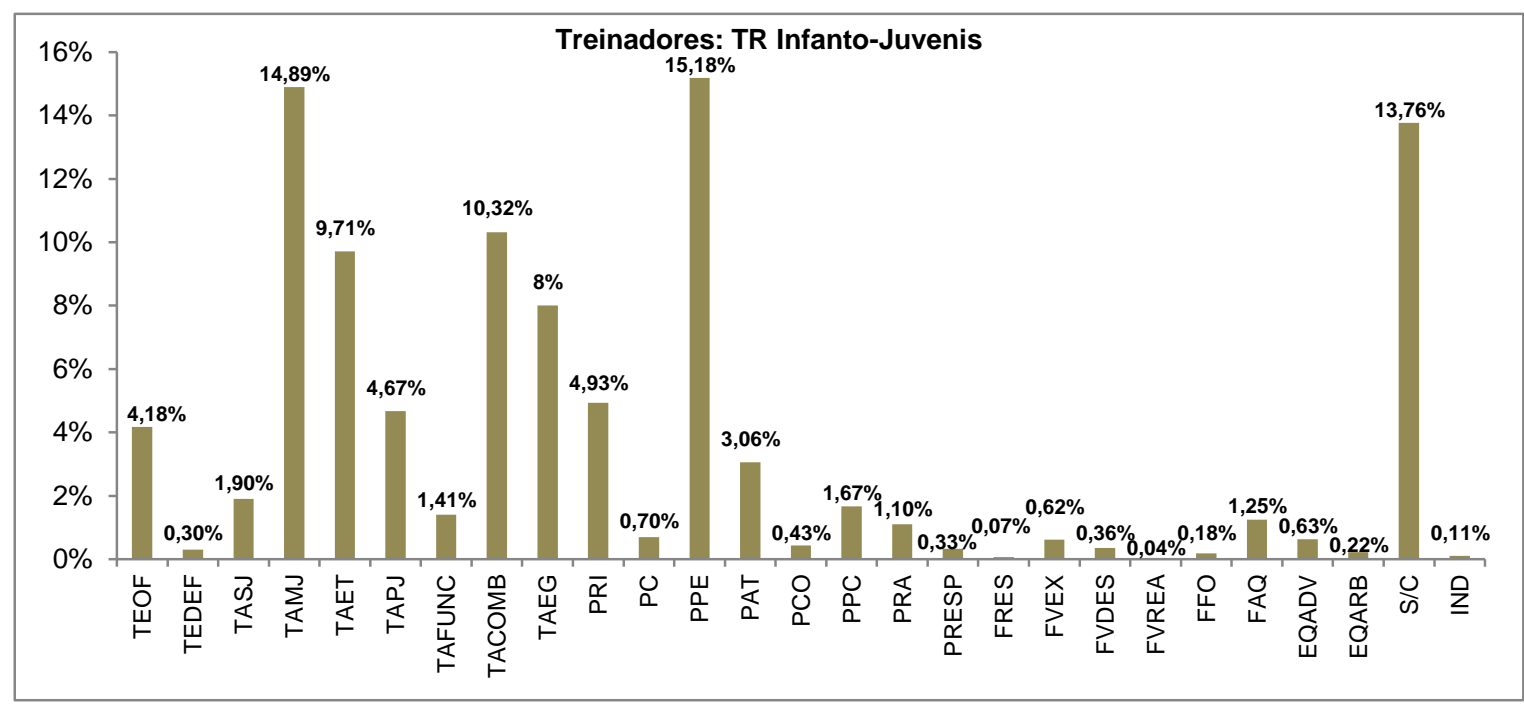

Figura 2. Valores em porcentagem das categorias/subcategorias da dimensão conteúdo durante a competição (TEOF - Técnicas Ofensivas; TEDEF - Técnicas Defensivas; TASJ - Tática de Sistema de Jogo; TAMJ - Tática de Método de Jogo; TAET - Tática dos Esquemas Táticos; TAPJ - Tática dos Principios de Jogo; TAFUNC - Táctica de Funções/Missões Especificas de Jogo; TACOMB - Tática das Combinações; TAEG - Tática Eficácia Geral; PRI - 
Psicológico Ritmo de Jogo; PC - Psicológico Confiança; PPE - Psicológico Pressão Eficácia; PAT - Psicológico Atenção; PCO - Psicológico Concentração; PPC - Psicológico Pressão Combatividade; PRA - Psicológico Resistências às Adversidades; PRESP - Psicológico Responsabilidade; FRES - Físico Resistência; FVEX - Físico Velocidade de Execução; FVDES - Físico Velocidade de Deslocamento; FVREA - Físico Velocidade de Reação; FFO - Físico Força; FAQ - Físico Aquecimento; EQADV - Equipa Adversária; EQARB - Equipa de Arbitragem; S/C - Sem Contéudo; IND - Indeterminado).

Ao analisarmos os resultados (Figura 2), não podemos deixar de registrar que, apesar do conteúdo tático ser o que apresenta maiores valores relativos, a subcategoria psicológica pressão eficácia $(15,18 \%)$ é que tem maior utilização por parte dos treinadores de equipes infanto-juvenis. A segunda subcategoria que apresenta maiores valores é relativa ao método de jogo defensivo e ofensivo da equipe $(14,89 \%)$, seguindo-se 0 conteúdo referente às combinações táticas (10,32\%).

Conforme valores apresentados na Figura 3, podemos verificar que atletas $(81,15 \%)$, atletas suplentes $(3,70 \%)$, grupo de atletas $(4,72 \%)$ e equipe $(9,12 \%)$ não mostram sinais evidentes de desatenção relativamente ao jogo ou ao treinador. Estes valores demonstram que os atletas e equipe têm comportamentos e/ou executam ações técnico-tácticas que procuram resolver as situações de jogo, estão ver e/ou ouvir as instruções emitidas pelo treinador.

Os treinadores de jovens da nossa amostra emitem uma quantidade média de instrução de 521,23 UI. Da quantidade média de instrução fornecida pelos treinadores somente $62,94 \%$ tem repercussões no comportamento dos atletas e equipe.

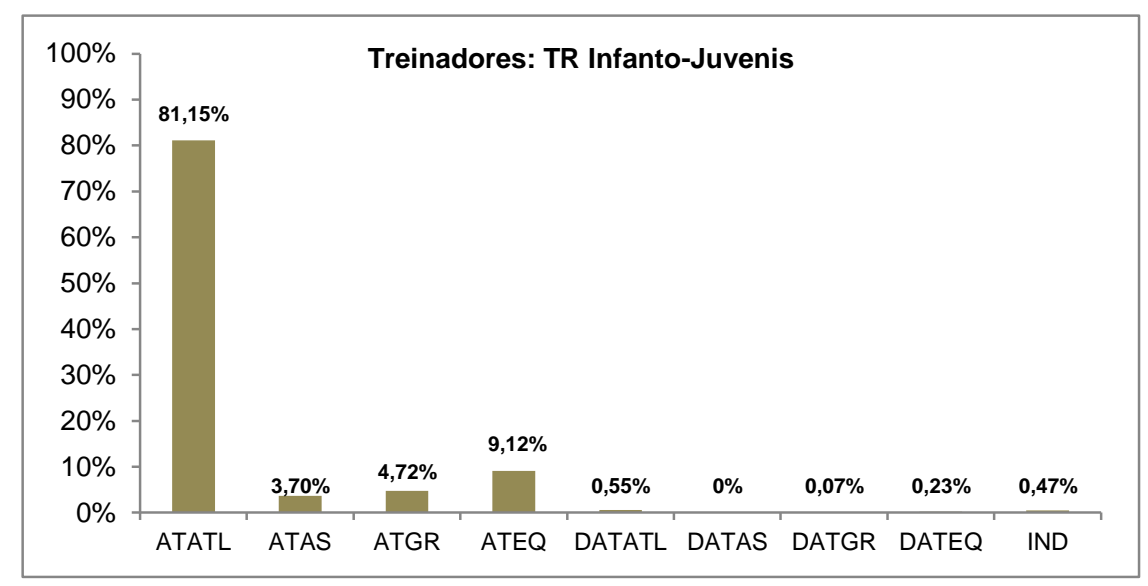

Figura 3. Valores em porcentagem da dimensão Atenção durante a competição (ATATL - Atenção Atleta; ATAS Atenção Atleta Suplente; ATGR - Atenção Grupo; ATEQ - Atenção Equipa; DATATL - Desatenção Atleta; DATAS Desatenção Atleta Suplente; DATGR - Desatenção Grupo; DATEQ - Desatenção Equipa; IND - Indeterminado).

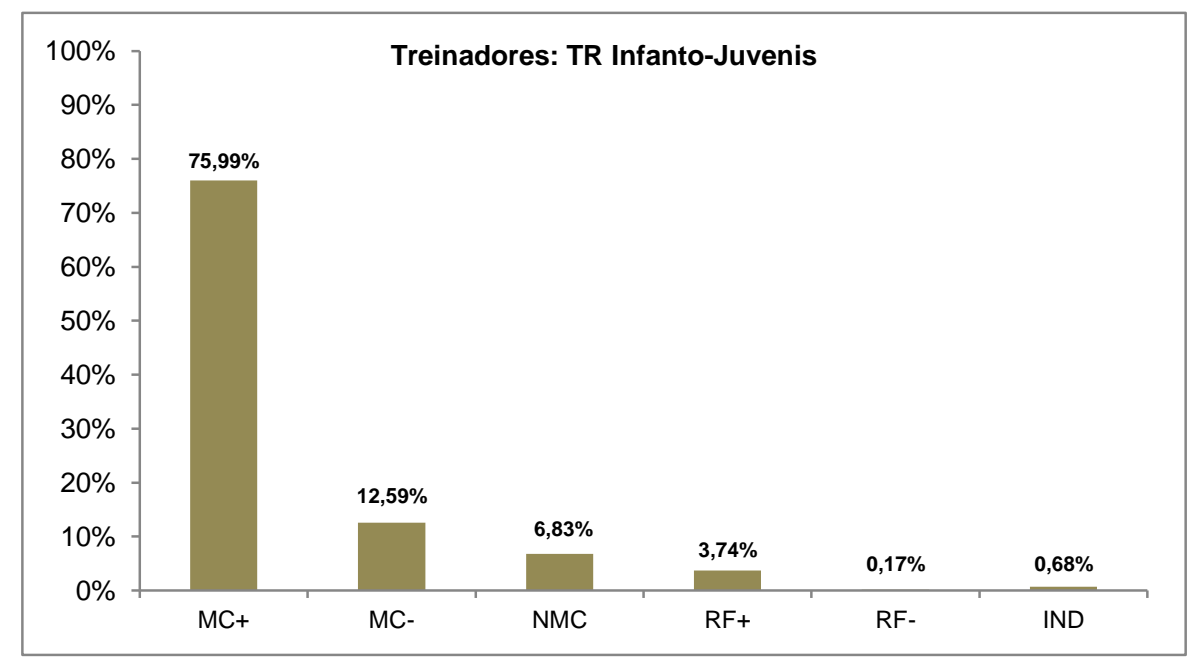

Figura 4. Valores em porcentagem da dimensão comportamento motor reativo durante a competição (MC+ - Modifica Comportamento Positivamente; MC- - Modifica o Comportamento Negativamente; NMC - Não Modifica O Comportamento; RF+ - Reforço Positivo; RF- - Reforço Negativo, IND - Indeterminado). 
Relativamente aos comportamentos imediatamente observáveis à emissão de instrução por parte do treinador (Figura 4), verifica-se que em $75,99 \%$, os atletas, grupo de atletas ou equipe modificam o comportamento positivamente, ou seja, o comportamento ou ação técnico-tática está de acordo com a informação transmitida e $12,59 \%$ das ocorrências modificam o comportamento negativamente. Os atletas e equipe não modificam o comportamento como resultado da instrução do treinador em 6,83\% das ocorrências registradas.

Os valores encontrados para as subcategorias reforços positivos (3,74\%) e reforços negativos $(0,17 \%)$ demonstram que o treinador faz avaliações positivas durante os comportamentos e ações técnico-táticas, levando os atletas a continuarem o que anteriormente foi valorizado.

\section{Treinadores de equipes de adultos}

O valor médio de unidades de informação por minuto é de 4,25 UI/MIN..

O objetivo da instrução (Figura 5) emitida pelos treinadores de equipes de adultos da nossa amostra é preferencialmente prescritivo $(80,17 \%)$, seguindo-se a categoria avaliativa positiva
$(8,28 \%)$, afetividade positiva (6,67\%) e descritiva $(2,54 \%)$.

Os treinadores de equipes de adultos emitiram instrução preferencialmente sob a forma auditiva $(69,14 \%)$, seguindo-se a forma auditiva-visual $(30,61 \%)$ e visual $(0,26 \%)$.

A direção da instrução emitida pelos treinadores de equipes de adultos é preferencialmente ao atleta $(75,17 \%)$, seguindose à equipe $(13,24 \%)$, atleta suplente $(5,89 \%)$ e grupo de meio de campo (3,55\%). A informação direcionada para os setores da equipe é de $5,05 \%$. Os treinadores de equipes de adultos procuraram emitir um conjunto de instruções aos atletas reservas $(5,89 \%)$ com o objetivo de utilizarem a substituição como meio operacional e objetivo de intervenção no jogo (astelo, 2009).

Os treinadores procuram preferencialmente emitir informação de conteúdo tático (49,32\%), seguindo-se o conteúdo psicológico (24,17\%), sem conteúdo $(17,40 \%)$, técnica $(3,78 \%)$, físico $(3,24 \%)$ e equipe adversária $(1,22 \%)$. Os valores registrados para as categorias equipe de arbitragem $(0,57 \%)$ e indeterminado $(0,01 \%)$ são muito baixos.

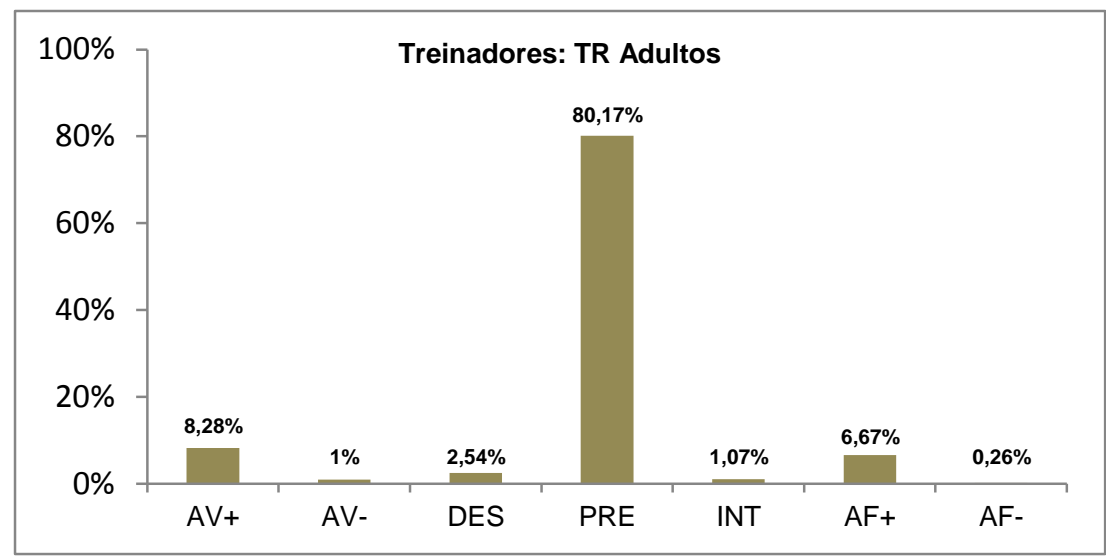

Figura 5. Valores em porcentagem da dimensão objetivo durante a competição (AV+ - Avaliativo Positivo; AV- Avaliativo Negativo; DES - Descritivo; INT - Interrogativo; AF+ - Afetivo Positivo; AF- - Afetivo Negativo).

Ao analisarmos a Figura 6, relativamente às duas categorias com maiores valores médios, verificamos que nos treinadores de equipes de adultos, a subcategoria com maior resultado é tática de método de jogo (19,71\%), seguindo-se a psicológica pressão para a eficácia $(13,09 \%)$ e tática de esquemas táticos (8,05\%).

$\mathrm{Na}$ dimensão atenção foram encontrados os seguintes valores: atletas $(73,50 \%)$, equipe $(12,96 \%)$, atleta reserva $(5,66 \%)$ e grupo de atletas (5,53\%) (Figura 7). Relativamente às subcategorias desatenção foram registrados valores bastantes baixos. Dessa forma, e tendo em conta que $97,67 \%$ das ocorrências são relativas às subcategorias atenção, podemos concluir que atletas, grupo de atletas e equipe, têm comportamentos e/ou executam ações técnico-táticas que procuram resolver as situações de jogo, e incluem ver e/ou ouvir as instruções emitidas pelo treinador. 


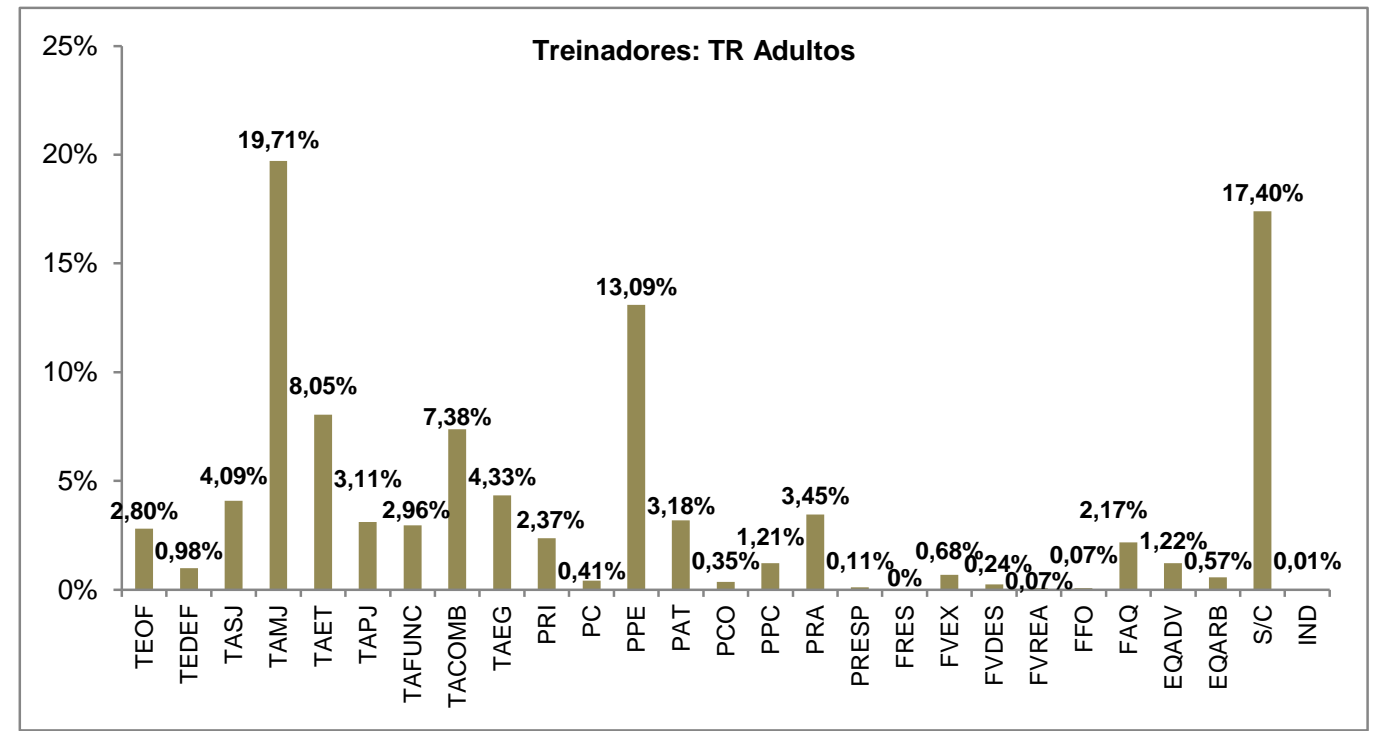

Figura 6. Valores em porcentagem das categorias/subcategorias da dimensão conteúdo durante a competição (TEOF - Técnicas Ofensivas; TEDEF - Técnicas Defensivas; TASJ - Tática de Sistema de Jogo; TAMJ - Tática de Método de Jogo; TAET - Tática dos Esquemas Táticos; TAPJ - Tática dos Princípios de Jogo; TAFUNC - Tática de Funções/Missões Especificas de Jogo; TACOMB - Tática das Combinações; TAEG - Tática Eficácia Geral; PRI Psicológico Ritmo de Jogo; PC - Psicológico Confiança; PPE - Psicológico Pressão Eficácia; PAT - Psicológico Atenção; PCO - Psicológico Concentração; PPC - Psicológico Pressão Combatividade; PRA - Psicológico Resistências às Adversidades; PRESP - Psicológico Responsabilidade; FRES - Físico Resistência; FVEX - Físico Velocidade de Execução; FVDES - Físico Velocidade de Deslocamento; FVREA - Físico Velocidade de Reação; FFO - Físico Força; FAQ - Físico Aquecimento; EQADV - Equipa Adversária; EQARB - Equipe de Arbitragem; S/C - Sem Contéudo; IND - Indeterminado).

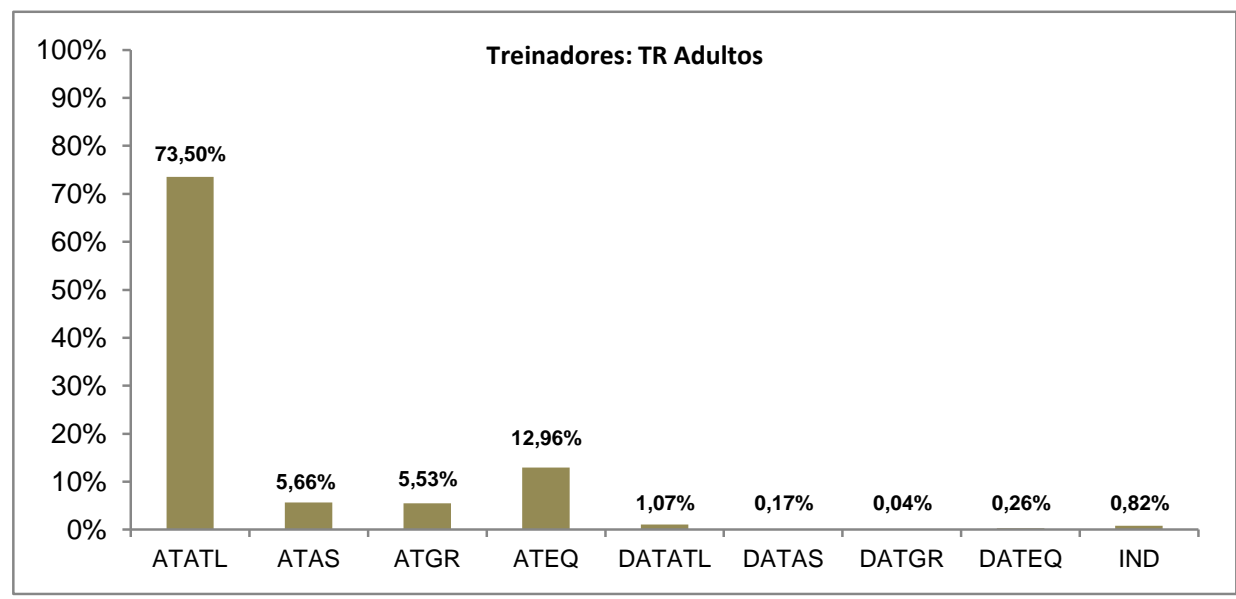

Figura 7. Valores em porcentagem da dimensão atenção durante a competição (ATATL - Atenção Atleta; ATAS Atenção Atleta Suplente; ATGR - Atenção Grupo; ATEQ - Atenção Equipe; DATATL - Desatenção Atleta; DATAS Desatenção Atleta Suplente; DATGR - Desatenção Grupo; DATEQ - Desatenção Equipe; IND - Indeterminado).

Os treinadores de equipes de adultos emitem em média uma quantidade de instrução de 413,08 $\mathrm{UI}$, sendo que somente $56,95 \%$ tem repercussões no comportamento imediatamente observável.

$\mathrm{Na}$ categoria modifica o comportamento, verifica-se o valor mais alto para subcategoria modifica o comportamento positivamente $(74,81 \%)$, seguindo-se as subcategorias modifica o comportamento negativamente $(8,41 \%)$ e não modifica o comportamento (8,29\%) (Figura 8). Estes valores demonstram que os atletas, grupo de atletas e equipe realizam comportamentos ou ações técnico-táticas de acordo com a instrução emitida pelo treinador.

$\mathrm{Na}$ categoria reforço, registramos para a subcategoria reforço positivo o valor de $6,33 \%$ e para a subcategoria reforço negativo de $0,71 \%$. Estes resultados demonstram que os treinadores de equipes de adultos avaliam/elogiam positivamente os atletas e equipe durante a execução das ações técnicotáticas/comportamentos, levando-os a continuar o que anteriormente foi valorizado. No entanto, se verificarmos os valores médios de instrução com 
objetivo de avaliar e elogiar positivamente e os compararmos com os resultados para 0 reforço positivo, podemos referir que os treinadores de equipes de adultos preferem emitir um juízo qualitativo sobre os comportamentos e ações técnico-táticas depois de elas acontecerem.

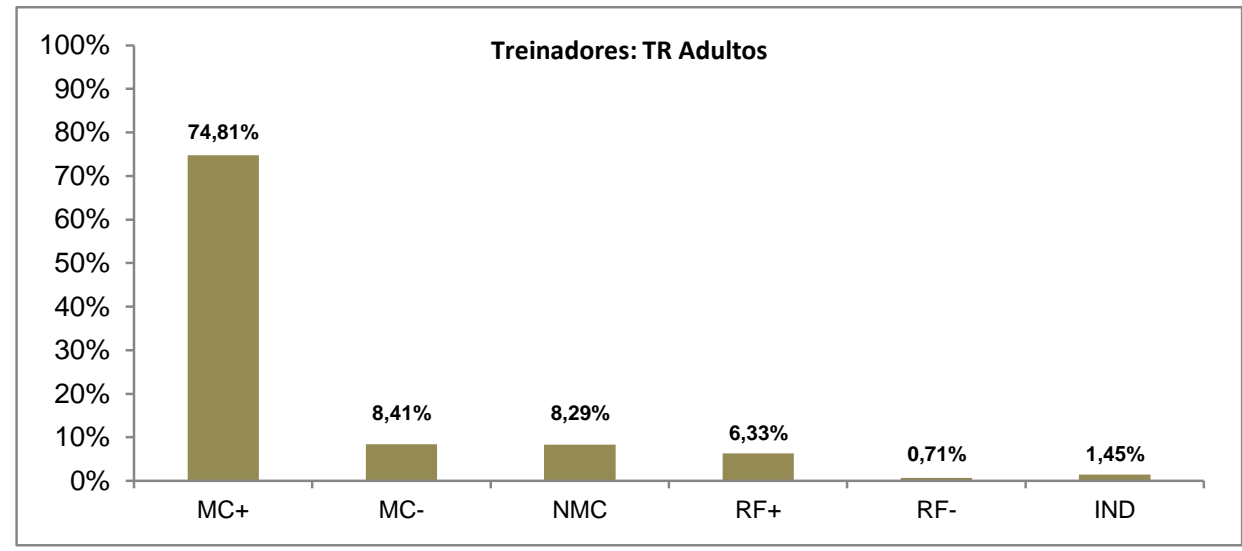

Figura 8. Valores em porcentagem da dimensão comportamento motor reativo durante a competição(MC+ - Modifica Comportamento Positivamente; MC- - Modifica o Comportamento Negativamente; NMC - Não Modifica o Comportamento; RF+ - Reforço Positivo; RF- - Reforço Negativo, IND - Indeterminado).

\section{Comparação entre treinadores de equipes infanto-juvenis e de adultos}

Relativamente à quantidade de instrução, os treinadores do setor de formação emitem mais instrução $(521,23 \mathrm{UI})$ comparativamente com os treinadores de equipes de adultos (413,08 UI), apresentando diferenças significativas entre os grupos $(p<0,000)$.

Tabela 1. Comparação na dimensão objetivo durante a competição.

\begin{tabular}{|c|c|c|c|}
\hline & Treinadores & Média & Sig. \\
\hline \multirow{2}{*}{$\begin{array}{l}\text { Avaliativo } \\
\text { positivo }\end{array}$} & Infanto-juvenis & 48,58 & 0,000 \\
\hline & Adultos & 34,21 & \\
\hline \multirow{2}{*}{ Descritivo } & Infanto-juvenis & 14,79 & 0,000 \\
\hline & Adultos & 10,51 & \\
\hline \multirow{2}{*}{ Prescritivo } & Infanto-juvenis & 419,08 & 0,000 \\
\hline & Adultos & 331,24 & \\
\hline \multirow{2}{*}{ Interrogativo } & Infanto-juvenis & 11,32 & 0,000 \\
\hline & Adultos & 4,44 & \\
\hline \multirow{2}{*}{$\begin{array}{c}\text { Afetividade } \\
\text { positiva }\end{array}$} & Infanto-juvenis & 20,71 & 0,002 \\
\hline & Adultos & 27,55 & \\
\hline \multirow{2}{*}{$\begin{array}{c}\text { Afetividade } \\
\text { negativa }\end{array}$} & Infanto-juvenis & 0,67 & 0,000 \\
\hline & Adultos & 1,09 & \\
\hline
\end{tabular}

Podemos constatar pela Tabela 1 que nas categorias estudadas da dimensão objetivo existem diferenças significativas na quantidade de instrução emitida, à exceção da categoria avaliativa negativa. Somente nas categorias afetividade positiva e negativa as diferenças se registram pela maior quantidade de instrução emitida pelos treinadores de equipes de adultos, significando que este grupo elogia e crítica com maior frequência a prestação dos atletas, grupo de atletas e equipe.

A forma preferencialmente utilizada pelos treinadores (equipes infanto-juvenis/adultos) observados é a auditiva, seguindo-se a auditivavisual. Os valores registrados para a categoria visual são quase insignificantes. Existem diferenças significativas entre os treinadores de equipes infanto-juvenis e de adultos na forma que utilizam para emitir instrução $(p<0,003)$. Em todas as categorias dessa dimensão os treinadores de jovens é que têm maiores valores (auditiva 382,00 Ul/285,65 UI; visual - 3,59 Ul/1,06 UI; auditiva-visual - 134,86 UI/126,45 UI).

A instrução, em ambos os grupos de treinadores analisados é dirigida preferencialmente ao atleta e equipe. É importante salientar que os treinadores de equipes infanto-juvenis $(23,39)$ emitem mais instrução na direção dos setores da equipe (defensivo, meio campo e avançado), comparativamente com os treinadores de equipes de adultos $(20,87)$. Nessa dimensão existem diferenças significativas entre os treinadores de equipes infanto-juvenis e de adultos nas categorias atletas, atleta reserva, grupo da defesa e grupo de meio de campo. Nas categorias atleta e grupo de defesas registram-se valores médios mais altos nos treinadores de equipes infanto-juvenis, enquanto que nas categorias atleta reserva e grupo de meio de campo, os valores médios mais altos registram-se nos treinadores de equipes de adultos. Não existem diferenças significativas nas categorias grupo de atacantes, grupo de reserva e equipe. 
Tabela 2. Comparação na dimensão conteúdo (técnica) da instrução durante a competição.

\begin{tabular}{llrr} 
& Treinadores & Média & Sig. \\
& & & \\
\hline Técnica & Infanto-juvenis & 21,81 & \multirow{2}{*}{0,025} \\
\cline { 2 - 3 } Ofensiva & Adultos & 11,57 & \\
\hline Técnica & Infanto-juvenis & 1,59 & \multirow{2}{*}{0,000} \\
\cline { 2 - 3 } Defensiva & Adultos & 4,06 & \\
\hline
\end{tabular}

Os treinadores de equipes infanto-juvenis emitem mais informação relativamente aos elementos técnicos ofensivos realizados pelos jogadores. Apesar de haver diferença significativa entre os dois grupos de treinadores observados nas subcategorias técnica ofensiva e defensiva, esta não se verifica na categoria técnica. Os treinadores de equipes infanto-juvenis emitem mais informação que os treinadores de equipes de adultos relativamente às técnicas ofensivas, e em relação às técnicas defensivas verifica-se o contrário.

Tabela 3. Comparação na dimensão conteúdo (tático) da instrução durante a competição.

\begin{tabular}{|c|c|c|c|}
\hline & Treinadores & Média & Sig. \\
\hline \multirow{2}{*}{$\begin{array}{l}\text { Tática sistema de } \\
\text { jogo }\end{array}$} & Infanto-juvenis & 9,91 & \multirow{2}{*}{0,000} \\
\hline & Adultos & 16,88 & \\
\hline \multirow{2}{*}{$\begin{array}{l}\text { Tática esquemas } \\
\text { táticos }\end{array}$} & Infanto-juvenis & 50,59 & \multirow{2}{*}{0,000} \\
\hline & Adultos & 33,25 & \\
\hline \multirow{2}{*}{$\begin{array}{l}\text { Tática princípios de } \\
\text { jogo }\end{array}$} & Infanto-juvenis & 24,33 & \multirow{2}{*}{0,000} \\
\hline & Adultos & 12,85 & \\
\hline \multirow{2}{*}{$\begin{array}{c}\text { Tática } \\
\text { missões/funções }\end{array}$} & Infanto-juvenis & 7,33 & \multirow{2}{*}{0,000} \\
\hline & Adultos & 12,23 & \\
\hline \multirow{2}{*}{ Tática combinações } & Infanto-juvenis & 53,80 & \multirow{2}{*}{0,000} \\
\hline & Adultos & 30,48 & \\
\hline \multirow{2}{*}{ Tática eficácia geral } & Infanto-juvenis & 41,72 & \multirow{2}{*}{0,000} \\
\hline & Adultos & 17,87 & \\
\hline
\end{tabular}

$\mathrm{Na}$ categoria tática, a instrução emitida é preferencialmente de conteúdo relativo ao método de jogo, esquemas táticos e combinações táticas. Ressaltamos que nos treinadores de equipes infanto-juvenis, a subcategoria tática combinações é a segunda com maior incidência e subcategoria esquemas táticos a terceira. Nos treinadores de equipes de adultos registra-se o contrário. Relativamente à subcategoria método de jogo, os treinadores de equipes de adultos fornecem mais informação com 0 referido conteúdo, no entanto não se verifica diferenças significativas relativamente aos treinadores de jovens. Nas restantes subcategorias existem diferenças significativas entre treinadores de equipes infanto-juvenis e de adultos. Há uma maior quantidade de instrução com conteúdo relacionado com os esquemas táticos, princípios de jogo, combinações táticas e tática eficácia geral nos treinadores de equipes infanto-juvenis. Nos treinadores de equipes de adultos, a maior quantidade de instrução registra-se nas subcategorias sistema de jogo, método de jogo e missões/funções específicas. De acordo com esses resultados podemos inferir que os treinadores de equipes infanto-juvenis procuram emitir instrução de conteúdo tático, procurando solidificar os aspectos fundamentais do jogo, tais como as combinações táticas simples diretas e indiretas, os princípios de jogo específicos ofensivos/defensivos e eficácia tática para a resolução das situações jogo, tendo em conta o contexto. Esses mesmos resultados levam-nos a apontar que a instrução emitida pelos treinadores de equipes de adultos resulta da observação do adversário, procurando explorar as fraquezas do mesmo, bem como minimizar as suas fortalezas e ao mesmo tempo cumprir o plano táticoestratégico definido para o jogo. No que concerne à categoria tática, existem diferenças significativas, sendo os treinadores de equipes infanto-juvenis aqueles que emitem a maior quantidade de instrução com esse conteúdo.

Tabela 4. Comparação na dimensão conteúdo (psicológico) da instrução durante a competição.

\begin{tabular}{|c|c|c|c|}
\hline & & & \\
\hline & Treinadores & Média & Sig. \\
\hline \multirow{2}{*}{ Psicológico ritmo de jogo } & Infanto-juvenis & 25,68 & \multirow{2}{*}{0,000} \\
\hline & Adultos & 9,77 & \\
\hline \multirow{2}{*}{ Psicológico confiança } & Infanto-juvenis & 3,67 & \multirow{2}{*}{0,003} \\
\hline & Adultos & 1,70 & \\
\hline \multirow{2}{*}{ Psicológico pressão eficácia } & Infanto-juvenis & 79,11 & \multirow{2}{*}{0,000} \\
\hline & Adultos & 54,08 & \\
\hline \multirow{2}{*}{ Psicológico atenção } & Infanto-juvenis & 15,94 & \multirow{2}{*}{0,000} \\
\hline & Adultos & 13,15 & \\
\hline \multirow{2}{*}{ Psicológico concentração } & Infanto-juvenis & 2,24 & \multirow{2}{*}{0,004} \\
\hline & Adultos & 1,43 & \\
\hline \multirow{2}{*}{ Psicológico pressão combatividade } & Infanto-juvenis & 8,68 & \multirow{2}{*}{0,000} \\
\hline & Adultos & 5,00 & \\
\hline \multirow{2}{*}{ Psicológico resistência às adversidades } & Infanto-juvenis & 5,72 & \multirow{2}{*}{0,000} \\
\hline & Adultos & 14,24 & \\
\hline \multirow{2}{*}{ Psicológico responsabilidade } & Infanto-juvenis & 1,70 & \multirow{2}{*}{0,000} \\
\hline & Adultos & 0,47 & \\
\hline
\end{tabular}


Relativamente à categoria psicológico verificase uma maior quantidade de instrução nos treinadores de equipes infanto-juvenis. Em todas as subcategorias relacionadas com a instrução de conteúdo psicológico existem diferenças significativas entre os treinadores de equipes infanto-juvenis e adultos. Somente na subcategoria psicológica resistência às adversidades se verifica por parte dos treinadores de adultos uma maior quantidade de emissão de instrução. Nas restantes subcategorias é registrada uma maior quantidade de instrução por parte dos treinadores de equipes infanto-juvenis. No conteúdo psicológico verifica-se ainda que os treinadores dos dois grupos observados emitem preferencialmente informação que procura pressionar os atletas e equipe para uma maior eficácia no jogo. Em seguida, vemos os treinadores de equipes infanto-juvenis as subcategorias com maior quantidade de instrução foi psicológico ritmo de jogo e psicológica atenção, enquanto que nos treinadores de equipes de adultos observamos as subcategorias psicológica resistência às adversidades $e$ psicológica atenção.

Tabela 5. Comparação na dimensão conteúdo (físico) da instrução durante a competição.

\begin{tabular}{|c|c|c|c|}
\hline & Treinadores & Média & Sig. \\
\hline \multirow{2}{*}{ Físico resistência } & Infanto-juvenis & 0,37 & \multirow{2}{*}{0,000} \\
\hline & Adultos & 0,00 & \\
\hline \multirow{2}{*}{$\begin{array}{l}\text { Físico velocidade de } \\
\text { deslocamento }\end{array}$} & Infanto-juvenis & 1,87 & \multirow{2}{*}{0,000} \\
\hline & Adultos & 1,00 & \\
\hline \multirow{2}{*}{$\begin{array}{l}\text { Físico velocidade de } \\
\text { reação }\end{array}$} & Infanto-juvenis & 0,23 & \multirow{2}{*}{0,000} \\
\hline & Adultos & 0,29 & \\
\hline \multirow{2}{*}{ Físico força } & Infanto-juvenis & 0,94 & \multirow{2}{*}{0,000} \\
\hline & Adultos & 0,31 & \\
\hline \multirow{2}{*}{ Físico aquecimento } & Infanto-juvenis & 6,50 & \multirow{2}{*}{0,000} \\
\hline & Adultos & 8,96 & \\
\hline
\end{tabular}

Em relação à categoria físico verificam-se diferenças significativas entre os treinadores de equipes infanto-juvenis e os treinadores de equipes de adultos, sendo estes últimos a emitir uma maior quantidade de instrução. Nesta categoria, somente a instrução com conteúdo relativo à velocidade de execução do jogador numa determinada tarefa/ação é que não exibe diferenças significativas entre os dois grupos de treinadores observados. Somente nas subcategorias físico velocidade de reação e físico aquecimento é que se verifica uma maior quantidade de instrução nos treinadores de equipes de adultos.

A categoria "sem conteúdo" apresenta valores altos nos dois grupos de treinadores observados, devido a emitirem uma quantidade grande de instrução com objetivo avaliativo e afetivo, mas que não tem conteúdo específico. Nesta categoria não existe diferenças significativas entre os treinadores de equipes infanto-juvenis e os treinadores de equipes de adultos.

Entre os treinadores do setor de formação e os treinadores de equipes de adultos diferenças significativas foram encontradas quanto à categoria equipe adversária e equipe de arbitragem. Os treinadores de equipes de adultos emitem mais informação sobre a equipe de arbitragem (5,03/3,26 UI), bem como informação com conteúdo sobre a equipe adversária $(2,35 / 1,14 \mathrm{UI})$.

Tabela 6. Comparação na dimensão atenção durante a competição.

\begin{tabular}{|c|c|c|c|}
\hline & Treinadores & Média & Sig. \\
\hline \multirow{2}{*}{ Atenção atleta } & Infanto-juvenis & 422,46 & \multirow{2}{*}{0,000} \\
\hline & Adultos & 303,61 & \\
\hline \multirow{2}{*}{$\begin{array}{l}\text { Atenção atleta } \\
\text { Reseva }\end{array}$} & Infanto-juvenis & 19,25 & \multirow{2}{*}{0,000} \\
\hline & Adultos & 23,38 & \\
\hline \multirow{2}{*}{ Atenção grupo } & Infanto-juvenis & 24,58 & \multirow{2}{*}{0,041} \\
\hline & Adultos & 22,86 & \\
\hline \multirow{2}{*}{ Desatenção atleta } & Infanto-juvenis & 2,87 & \multirow{2}{*}{0,000} \\
\hline & Adultos & 4,41 & \\
\hline \multirow{2}{*}{$\begin{array}{l}\text { Desatenção atleta } \\
\text { Reserva }\end{array}$} & Infanto-juvenis & 0,00 & \multirow{2}{*}{0,000} \\
\hline & Adultos & 0,69 & \\
\hline \multirow{2}{*}{ Desatenção grupo } & Infanto-juvenis & 0,35 & \multirow{2}{*}{0,000} \\
\hline & Adultos & 0,16 & \\
\hline
\end{tabular}

Relativamente à dimensão atenção verifica-se na maioria das categorias que existem diferenças significativas entre os treinadores de equipes infanto-juvenis e de adultos, à exceção das categorias atenção equipe e desatenção equipe. Os resultados apresentados demonstram a tendência quanto à direção da instrução emitida e, na grande maioria das ocorrências, os atletas, grupos de atletas e equipe revelam estar atentos. Os maiores valores médios para os treinadores de equipes infanto-juvenis registram-se nas categorias atenção atleta, atenção grupo, desatenção grupo e desatenção equipe, enquanto que nos treinadores de equipes de adultos, os valores altos ocorrem nas categorias atenção atleta reserva, atenção equipe, desatenção atleta, desatenção atleta reserva. Dos resultados apresentados sobressai que apesar dos 
treinadores de equipes de adultos terem valores médios mais baixos na categoria atenção atleta, apresentam valores mais altos na categoria desatenção atleta relativamente aos treinadores de equipes infanto-juvenis. Tal fato também se verifica nos treinadores de equipes infantojuvenis, apesar de não haver diferenças significativas, para as categorias atenção equipe/desatenção equipe.

Tabela 7. Comparação na dimensão comportamento motor reativo durante a competição.

\begin{tabular}{|c|c|c|c|}
\hline & Treinadores & Média & Sig. \\
\hline \multirow{2}{*}{$\begin{array}{l}\text { Modifica o } \\
\text { comportamento } \\
\text { positivamente }\end{array}$} & Infanto-juvenis & 249,34 & \multirow[b]{2}{*}{0,000} \\
\hline & Adultos & 176,02 & \\
\hline \multirow{2}{*}{$\begin{array}{l}\text { Modifica o } \\
\text { comportamento } \\
\text { negativamente }\end{array}$} & Infanto-juvenis & 41,31 & \multirow{2}{*}{0,000} \\
\hline & Adultos & 19,79 & \\
\hline \multirow{2}{*}{$\begin{array}{l}\text { Não modifica o } \\
\text { comportamento }\end{array}$} & Infanto-juvenis & 22,40 & \multirow{2}{*}{0,000} \\
\hline & Adultos & 19,51 & \\
\hline \multirow{2}{*}{ Reforço negativo } & Infanto-juvenis & 0,56 & \multirow{2}{*}{0,000} \\
\hline & Adultos & 1,67 & \\
\hline
\end{tabular}

Os atletas, grupo de atletas e equipe modificam o comportamento de acordo com a instrução emitida pelos treinadores. Em todas as categorias, exceto na categoria reforço positivo, encontramos diferenças significativas entre os dois grupos de treinadores.

\section{Discussão}

Os jogos observados e resultados extraídos permitem-nos aferir que, globalmente, o comportamento de instrução, bem como a atenção dos atletas e equipe ao aporte de informação e comportamento motor reativo, apresentam diferenças nos treinadores de equipes infanto-juvenis e de adultos.

Os treinadores observados emitem instrução com o objetivo de prescrever comportamentos e ações técnico-táticas mais eficazes para a resolução das situações de jogo e avaliar/elogiar positivamente. A forma de efetuar o aporte de informação é preferencialmente auditiva, embora haja também uma preocupação dos treinadores em utilizar a forma auditiva-visual. A direção da instrução é predominantemente ao indivíduo, seguindo-se à equipe. No que concerne ao conteúdo da instrução é tático, seguindo-se o conteúdo psicológico. Nos dois grupos verificamse valores altos para a instrução sem conteúdo, resultante do objetivo avaliativo/afetivo que é desprovido de qualquer conteúdo. Nos treinadores de equipes infanto-juvenis $e$ treinadores de equipes de adultos, os atletas, grupo de atletas e equipe demonstram estar atentos à informação emitida, modificando o comportamento de acordo com a instrução fornecida.

Apuramos que os treinadores de equipes infanto-juvenis (6,3 UI/Min.) apresentam significativamente mais quantidade de instrução que os treinadores de equipes de adultos $(4,25$ UI/Min.) durante a competição.

Confirmou-se a existência de algumas diferenças significativas entre os treinadores de equipes infanto-juvenis e adultos, exceto nas categorias avaliativo negativo (dimensão objetivo), grupo de atacantes, grupo de reservas, equipe (dimensão direção), técnica (dimensão conteúdo), nas subcategorias tática método de jogo (categoria tático - dimensão conteúdo), físico velocidade de execução (categoria físico dimensão conteúdo) e sem conteúdo. Na atenção prestada pelo(s) atleta(s) e equipe ao aporte de informação existem diferenças significativas entre treinadores de equipes infanto-juvenis e de adultos, exceto quando o aporte de informação é direcionado à equipe. Quanto à dimensão modificação do comportamento do(s) atleta(s) e equipe resultante do aporte de informação também há diferenças significativas entre os treinadores de equipes infanto-juvenis e de adultos, com exceção da categoria de reforço positivo.

\section{Referências}

CARTER, A.; BLOOM, G. Coaching knowledge and success: going beyond athletic experiences. Journal of Sport Behavior, New York, v. 32, n. 4, p.419-437, 2009.

\section{CASTELO, J. Futebol. Organização dinâmica}

do jogo. $3^{\text {a }}$ Ed.. Lisboa: Centro de Estudos de Futebol da Universidade Lusófona de Humanidades e Tecnologias. 2009.

COTÉ, J.; YOUNG, B.; NORTH, J.; DUFFY, P. Towards a definition of excellence in sport coaching. International Journal of Coaching

Science, Ottawa, v. 1, n. 1, p. 3-16, 2007. Disponível em:

$<$ http://www.queensu.ca/skhs/ContactUs-

2/Faculty-1/Faculty-

JeanCote/CotePublications/CotePublications2007/ CoteetallJCS.pdf>. Acesso em: 20 jan. 2011.

GILBERT, W.; TRUDEL, P.; HAUGHAN, L.P. Interactive decision making factors considered by coaches of youth ice hockey during games.

Journal of teaching in Physical Education, Champaign, v. 18, p. 290-311, 1999. 
LAUNDER, A.; PILTZ, W. Becoming a better bench coach. Part 2: Coaching in the game. Sportscoach, Belbonnen, p. 26-27, Autumn, 1999.

MESQUITA, I.; ROSADO, A.; JANUÁRIO, N.; BARROJA, E. Athlete's retention of coach's instruction before a judo competion. Journal of Sports Science and Medicine, Bursa, v. 7, p. 402-407, 2008. Disponível em: <http://www.jssm.org/vol7/n3/13/v7n3-13pdf.pdf>. Acesso em: 24 jan. 2011.

MESQUITA, I.; SOBRINHO, A.; ROSADO, A.; PEREIRA, F.; MILISTETD, M. A systematic observation of youth amateur volleyball coaches behaviours. International Journal of Applied

Sports Sciences, Nowon-gu, v. 20, n. 2, p. 37-58, 2008

MORENO, M.P.; SANTOS, J.A.; RAMOS, L.A.; CERVELLÓ, E.; IGLESIAS, D.; DEL VILLAR, F. The Efficacy of the verbal behaviour of volleyball coaches during competition. European Journal of Human Movement, Cáceres, v. 13, p. 55-69, 2005. Disponível em:

$<$ http://dialnet.unirioja.es/servlet/articulo?codigo $=2$ 279074>. Acesso em: 20 jan. 2011.

MORENO, M.P.; ÁLVAREZ, F. El entrenador deportivo. Manual práctico para su desarrollo y formacion. 1 1 Ed. Barcelona: INDE

Publicacions, 2004.

RAMIREZ, J.; DIAZ, M. El papel educativo y la responsabilidade los entrenadores desportivos. Una investigacion sobre la instrucciones a escolares en fútbol de compéticion. Revista de Educacion, Madrid, v. 335, p. 163-187, 2004. Disponível em:

$<$ http://www.google.com/books?hl=pt-

PT\&lr=\&id=AYpnglUaQtQC\&oi=fnd\&pg=PA163\&d q=RAMIREZ $,+J . \% 3 B+D I A Z,+M . .+E I+$ papel+educa tivo+y+la+responsabilidade+los+entrenadores+de sportivos.+Una+investigacion+sobre+la+instruccio nes+a+escolares+en+f\%C3\%BAtbol+de+comp\% C3\%A9ticion.+Revista+de+Educacion\&ots $=8 \mathrm{sLO}$ Xm2 Kx\&sig=q8RgOAUTbYbTuPN0ndzAS57 iE\#v=onepage\& $q \& f=f$ alse >. Acesso em: 24 jan. 2011.

SANTOS, A.; RODRIGUES, J. Análise da Instrução do Treinador de Futebol. Comparação entre a Prelecção de Preparação e a Competição. Fitness \& Performance Journal, Rio de Janeiro, v. 7, n. 2, p. 112-122, 2008. Disponível em: $<$ http://dx.doi.org/10.3900/fpj.7.2.112.p >. Acesso em: 24 jan. 2011.

SMITH, R.; SMOLL, F. Coaching the coaches: youth sports as scientific and applied behavioral setting. Current Directions in Psychological Science, Oxford, v. 6, n. 1, p. 16-21, 1997.

\section{Endereço:}

Fernando Jorge Lourenço dos Santos Avenida Dr. Mário Soares, Pavilhão Multiusos Rio Maior Portugal ZIP: 2040-430

Phone: +351 243999 280, +351 243999292 e-mail: filsantos@gmail.com

Recebido em: 15 de fevereiro de 2011. Aceito em: 29 de novembro de 2011.

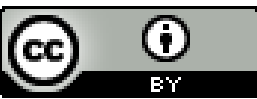

Motriz. Revista de Educação Física. UNESP, Rio Claro, SP, Brasil - elSSN: 1980-6574 - está licenciada sob Creative Commons - Atribuicão 3.0 